Article

\title{
Inherently Area-Selective Atomic Layer Deposition of Manganese Oxide through Electronegativity-Induced Adsorption
}

\author{
Yi-Cheng Li ${ }^{1}$, Kun Cao ${ }^{1, *}$, Yu-Xiao Lan ${ }^{2}$, Jing-Ming Zhang ${ }^{2}$, Miao Gong ${ }^{1}$, Yan-Wei Wen ${ }^{2}$, Bin Shan ${ }^{2}$ \\ and Rong Chen ${ }^{1, *}$
}

1 State Key Laboratory of Digital Manufacturing Equipment and Technology, School of Mechanical Science and Engineering, Huazhong University of Science and Technology, 1037 Luoyu Road, Wuhan 430063, China; yichengli@hust.edu.cn (Y.-C.L.); miaogong@hust.edu.cn (M.G.)

2 State Key Laboratory of Materials Processing and Die \& Mould Technology, School of Materials Science and Engineering, Huazhong University of Science and Technology, 1037 Luoyu Road, Wuhan 430063, China; M202070873@hust.edu.cn (Y.-X.L.); simonzjm666@gmail.com (J.-M.Z.); ywwen@hust.edu.cn (Y.-W.W.); bshan@mail.hust.edu.cn (B.S.)

* Correspondence: kuncao@mail.hust.edu.cn (K.C.); rongchen@mail.hust.edu (R.C.)

check for updates

Citation: Li, Y.-C.; Cao, K.; Lan, Y.-X. Zhang, J.-M.; Gong, M.; Wen, Y.-W.; Shan, B.; Chen, R. Inherently

Area-Selective Atomic Layer Deposition of Manganese Oxide through Electronegativity-Induced Adsorption. Molecules 2021, 26, 3056. https://doi.org/10.3390/ molecules26103056

Academic Editor: Silvia Armini

Received: 14 April 2021

Accepted: 17 May 2021

Published: 20 May 2021

Publisher's Note: MDPI stays neutral with regard to jurisdictional claims in published maps and institutional affiliations.

Copyright: (c) 2021 by the authors. Licensee MDPI, Basel, Switzerland. This article is an open access article distributed under the terms and conditions of the Creative Commons Attribution (CC BY) license (https:/ / creativecommons.org/licenses/by/ $4.0 /)$.

\begin{abstract}
Manganese oxide $\left(\mathrm{MnO}_{\mathrm{x}}\right)$ shows great potential in the areas of nano-electronics, magnetic devices and so on. Since the characteristics of precise thickness control at the atomic level and self-align lateral patterning, area-selective deposition (ASD) of the $\mathrm{MnO}_{\mathrm{x}}$ films can be used in some key steps of nanomanufacturing. In this work, $\mathrm{MnO}_{\mathrm{x}}$ films are deposited on $\mathrm{Pt}, \mathrm{Cu}$ and $\mathrm{SiO}_{2}$ substrates using $\mathrm{Mn}(\mathrm{EtCp})_{2}$ and $\mathrm{H}_{2} \mathrm{O}$ over a temperature range of $80-215^{\circ} \mathrm{C}$. Inherently areaselective atomic layer deposition (ALD) of $\mathrm{MnO}_{\mathrm{x}}$ is successfully achieved on metal $/ \mathrm{SiO}_{2}$ patterns. The selectivity improves with increasing deposition temperature within the ALD window. Moreover, it is demonstrated that with the decrease of electronegativity differences between $\mathrm{M}(\mathrm{M}=\mathrm{Si}, \mathrm{Cu}$ and $\mathrm{Pt}$ ) and $\mathrm{O}$, the chemisorption energy barrier decreases, which affects the initial nucleation rate. The inherent ASD aroused by the electronegativity differences shows a possible method for further development and prediction of ASD processes.
\end{abstract}

Keywords: area selective; atomic layer deposition; manganese oxide

\section{Introduction}

Area-selective deposition (ASD), including area-selective atomic layer deposition (ALD), is considered a prospective way to downscale nano-electronics [1-3]. ALD takes advantage of self-limiting reactions to achieve conformal thin film growth with atomic-level thickness control [4]. The ALD reactions are extremely sensitive to surface chemistry due to the self-limiting nature [5]. Firstly, the activity of the precursors and steric hindrance from the ligands affect the density of chemisorption [6]. Meanwhile, the type and density of surface-active sites have an important role in the growth rate of target materials [7]. It is generally considered that the $\mathrm{O}^{*}, \mathrm{H}^{*}$ and $-\mathrm{OH}$ are the active sites for the precursors chemisorption [8-10]. In some conditions, the byproducts or impurities may poison the surface and prevent additional adsorption of the precursors [11,12]. Moreover, a surface with catalytic activity can promote ALD growth $[13,14]$. When the driving force of nucleation is between the Gibbs free energy barriers of two different surfaces, the nuclei form rapidly on a surface with a low-energy barrier rather than on the other. Thus, ideal area-selective ALD can be realized through nuclei inhibition on the nongrowth areas. The selective deposition is quite complicated and relies on the coupled parameters, including substrates, precursors, temperature, pressure and aspect ratio dependency. Prior reports showed that the selectivity could be obtained by chemical modification, including surface passivation with polymers, self-assembled monolayers (SAMs), inhibitors and so on [15-17]. 
The above methods achieve high selectivity for nano-feature patterning but have limitations in long passivation time and complex steps. Thus, inherently selective deposition has been investigated to relax process complexity [18]. Up to now, four types of ASD have been reported, including DoD, DoM, MoD and MoM (M = metal, D = dielectric). Among them, selective deposition of oxides on metal can be used as barrier or capping layers to improve device performance.

ALD- $\mathrm{MnO}_{\mathrm{x}}$ has been studied and utilized to reduce the overall interconnect resistance in microelectronics [19]. It was also applicable to energy storage and conversion [20], magnetic devices [21] and so on. Previous studies demonstrated that the manganese oxide was fabricated by ALD using bis(ethylcyclopentadienyl) manganese $\left(\mathrm{Mn}(\mathrm{EtCp})_{2}\right)$ and water $\left(\mathrm{H}_{2} \mathrm{O}\right)[22,23]$ or tris(2,2,6,6-tetramethyl-3,5-heptanedionato) manganese $\left(\mathrm{Mn}(\mathrm{thd})_{3}\right)$ and ozone $\left(\mathrm{O}_{3}\right)$ [24] as precursors. The $\mathrm{MnO}_{\mathrm{x}}$ layer was conformally deposited in the high aspect-ratio structures, and the $\sim 1 \mathrm{~nm}$ thin film showed great diffusion barrier properties [25]. Usually, the deposition took place on the entire surface and needed auxiliary etching to obtain nanopatterns. Kawasaki et al. found that the selective deposition of $\mathrm{MnO}_{\mathrm{x}}$ existed between $\mathrm{Cu}$ and low-k SiCOH films, and the nucleation delay on $\mathrm{SiCOH}$ films is just a few cycles [26]. Moreover, they found that the native oxide layer on $\mathrm{Cu}$ is in favor of an ALD reaction compared with non-oxidized $\mathrm{Cu}$. Phuong et al. discovered that plasma-treated and as-received SiOC substrates had different deposition rates of $\mathrm{MnO}_{\mathrm{x}}$ [27]. It was found that moisture was adsorbed on the matrix after plasma treatment and acted as a catalyst for $\mathrm{MnO}_{\mathrm{x}}$ deposition. The chemical bond between the deposited oxide and the substrate is $\mathrm{M}-\mathrm{O}-\mathrm{Mn}(\mathrm{M}=$ metal, metalloid), and the chemical state of the surface oxygen group is the key issue. Previous reports established a relationship between the type of oxygen species and the nucleation rate [28]. Therefore, it is of great significance to study the surface chemistry and reaction mechanism to obtain high selectivity.

In this article, $\mathrm{MnO}_{\mathrm{x}}$ is deposited on metal $/ \mathrm{SiO}_{2}$ patterns using $\mathrm{Mn}(\mathrm{EtCp})_{2}$ precursors with $\mathrm{H}_{2} \mathrm{O}$ as co-reactant. The X-ray photoelectron spectroscopy (XPS) shows that the Mn (II) precursors are oxidized, and the substrates are reduced after the ALD process. Additionally, the surface oxygen group plays an important role in chemisorption. The selectivity is quantified by EDS mapping, and the selectivity is optimized by adjusting deposition temperature. Meanwhile, it was found that selectivity has a relationship with the electronegativity differences. The differences in electronegativity decrease in the order of $\mathrm{Si}-\mathrm{O}(1.54), \mathrm{Cu}-\mathrm{O}(1.44)$ and $\mathrm{Pt}-\mathrm{O}$ (1.16). On the contrary, the deposition rate is negatively related to the electronegativity differences. It is conducive to the formation of $\mathrm{M}-\mathrm{O}-\mathrm{Mn}$ $(\mathrm{M}=$ metal, metalloid) bonds in areas with a low difference in electronegativity.

\section{Results}

\subsection{Characterization of Selectivity}

The schematic diagram of $\mathrm{MnO}_{\mathrm{x}}$ deposited on metal $/ \mathrm{SiO}_{2}$ patterns is shown in Figure 1a. The patterns consist of $60 \mu \mathrm{m}$ metal-capped lines. There are sharp boundaries between the metal and exposed $\mathrm{SiO}_{2} / \mathrm{Si}$ areas (Figure $\mathrm{S} 1$ from Supplementary Materials). After 50 ALD $\mathrm{MnO}_{x}$ cycles, the amplified border areas are characterized with SEM and EDS. Figure 1 shows EDS mapping of $\mathrm{Pt}$ and $\mathrm{Mn}$ on $\mathrm{Pt} / \mathrm{SiO}_{2}$ patterns at 80, 125 and $215^{\circ} \mathrm{C}$, respectively. The green and white points represent $\mathrm{Pt}$ and $\mathrm{Mn}$ elements, respectively. It is found that the density of white points $(\mathrm{Mn})$ on the Pt surface is higher than that on the $\mathrm{SiO}_{2} / \mathrm{Si}$ surface, indicating that $\mathrm{MnO}_{\mathrm{x}}$ grows faster on the Pt surface. The white points decrease on the nongrowth $\mathrm{SiO}_{2}$ regions with increasing deposition temperature, indicating that the selectivity is improved. The temperature adjustment can enlarge the differences in the deposition rates on different substrates. The quantitative values of selectivity and the corresponding selectivity window are presented in the following parts. 

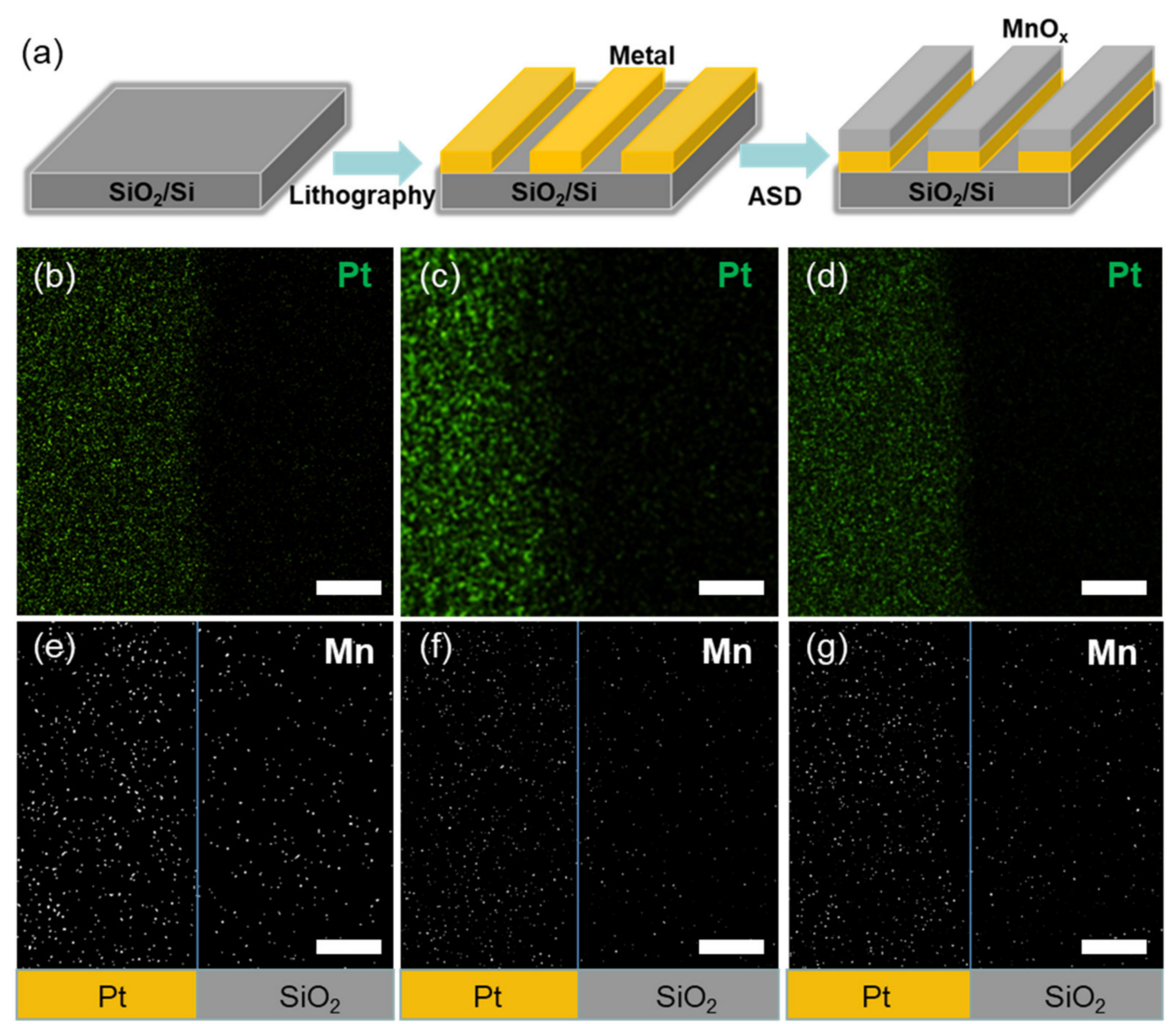

Figure 1. (a) A sketch of the area-selective ALD on metal/ $\mathrm{SiO}_{2}$ substrates patterned by lithography. EDS mappings of platinum and manganese on $\mathrm{Pt} / \mathrm{SiO}_{2}$ patterns after $50 \mathrm{ALD} \mathrm{MnO}_{\mathrm{x}}$ cycles, respectively. (b) Platinum and (e) manganese at $80{ }^{\circ} \mathrm{C}$, (c) platinum and (f) manganese at $125^{\circ} \mathrm{C}$, and (d) platinum and (g) manganese at $215^{\circ} \mathrm{C}$. The scale bar is $200 \mathrm{~nm}$.

\subsection{Surface Composition of $\mathrm{MnO}_{x}$ Deposited on Different Substrates}

The substrates' surfaces affect nucleation behaviors of selective deposition and subsequent quality of target materials. To identify the influences of surface species during ALD, the composition of $\mathrm{MnO}_{x}$ deposited on $\mathrm{Pt}, \mathrm{Cu}$ and $\mathrm{SiO}_{2}$ substrates are analyzed by XPS. Firstly, the appearance of $\mathrm{Mn}$ peak indicates that $\mathrm{MnO}_{\mathrm{x}}$ is grown on three kinds of substrates. The Mn $2 p$ spectrum (Figure 2a) shows two peaks corresponding to the $\mathrm{Mn}$ $2 \mathrm{p}_{3 / 2}$ and $\mathrm{Mn} 2 \mathrm{p}_{1 / 2}$ core levels centered at binding energies of $\sim 653.0 \mathrm{eV}$ and $\sim 642.0 \mathrm{eV}$, respectively $[29,30]$. After the spectra fitting analysis, the $\mathrm{Mn} 2 \mathrm{p}_{3 / 2}$ spectra are separated with four peaks located at around 641.1-641.3 eV, 642.1-642.6 eV, 644.0-644.3 eV and 646.5-647.0 eV, which correspond to $\mathrm{Mn}^{2+}, \mathrm{Mn}^{3+}, \mathrm{Mn}^{4+}$ and $\mathrm{Mn}^{2+}$ satellite bonds, respectively. It is found that there are three valence states of $\mathrm{Mn}$ element on $\mathrm{Pt}$ and $\mathrm{SiO}_{2}$ surface, while there is no tetravalent $\mathrm{Mn}$ on $\mathrm{Cu}$ surface.

The $\mathrm{Mn}(\mathrm{EtCp})_{2}$ precursor is a reducing agent due to its unsaturated -EtCp ligands. Thus, the $\mathrm{MnO}_{\mathrm{x}}$ film presents higher valences due to oxidation during the ALD process. The percentage of tetravalent $\mathrm{Mn}$ on $\mathrm{Pt}$ is higher than that on the $\mathrm{SiO}_{2}$ surface. This is perhaps because of the catalytic activity of Pt. Previous studies attributed ASD of metal oxides (such as $\mathrm{FeO}_{\mathrm{x}}, \mathrm{CeO}_{\mathrm{x}}$ ) on $\mathrm{Pt} / \mathrm{SiO}_{2}$ patterns to catalytic activation of oxygen that increase nucleation rate on $\mathrm{Pt}$ [31]. Due to the high activity of surface oxygen species on $\mathrm{Pt}$, it is easier for the precursor's adsorption and decomposition, thus leading to high selectivity. 

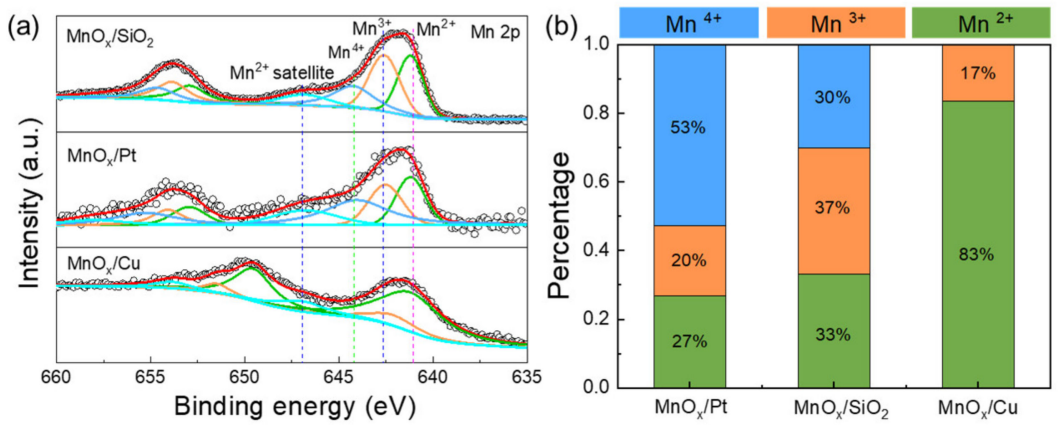

Figure 2. (a) Mn 2p XPS spectra of 50 ALD cycles on $\mathrm{Cu}, \mathrm{Pt}$ and $\mathrm{SiO}_{2}$ substrates. (b) A comparison of bond information regarding the elements of $\mathrm{Mn}$ for the $\mathrm{ALD} \mathrm{MnO}_{\mathrm{x}}$ obtained from the XPS measurements.

To analyze the role of surface oxygen species, the $\mathrm{SiO}_{2} / \mathrm{Si}, \mathrm{Pt}$ and $\mathrm{Cu}$ substrates before and after $\mathrm{MnO}_{\mathrm{x}}$ deposition are measured with XPS and presented in Figure 3. All of the substrates are reduced in a $10 \%$ hydrogen mixture at $125{ }^{\circ} \mathrm{C}$, and then the substrates are transferred into the ALD reactor to deposit $\mathrm{MnO}_{\mathrm{x}}$. It is found that $\mathrm{Pt}$ and $\mathrm{Cu}$ substrates are partially oxidized before the ALD process, although the substrates are already reduced. Hence, surface oxygen species will affect the nucleation behaviors during selective deposition. After 50 ALD cycles, $\mathrm{Pt}$ is slightly reduced, while the $\mathrm{Cu}$ substrate is obviously reduced (Figure 3b,c). The electron transfer occurs between the substrate and the Mn precursors, which results in the reduction of the substrate [30]. The surface oxygen species act as active sites for $\mathrm{MnO}_{\mathrm{x}}$ deposition. The rapid disappearance of $\mathrm{CuO}$ may lead to a great decrease of active sites and the weakening of the electron-stripping ability of the substrate, resulting in the absence of tetravalent manganese. Additionally, the O 1s XPS spectrum of $\mathrm{SiO}_{2} / \mathrm{Si}, \mathrm{Pt}$ and $\mathrm{Cu}$ substrates are presented. After the $\mathrm{MnO}_{\mathrm{x}}$ deposition, the content of lattice oxygen is more than that of the bare substrate without deposition. The increase of lattice oxygen may contribute to the $\mathrm{Mn}-\mathrm{O}$ bonds after deposition.
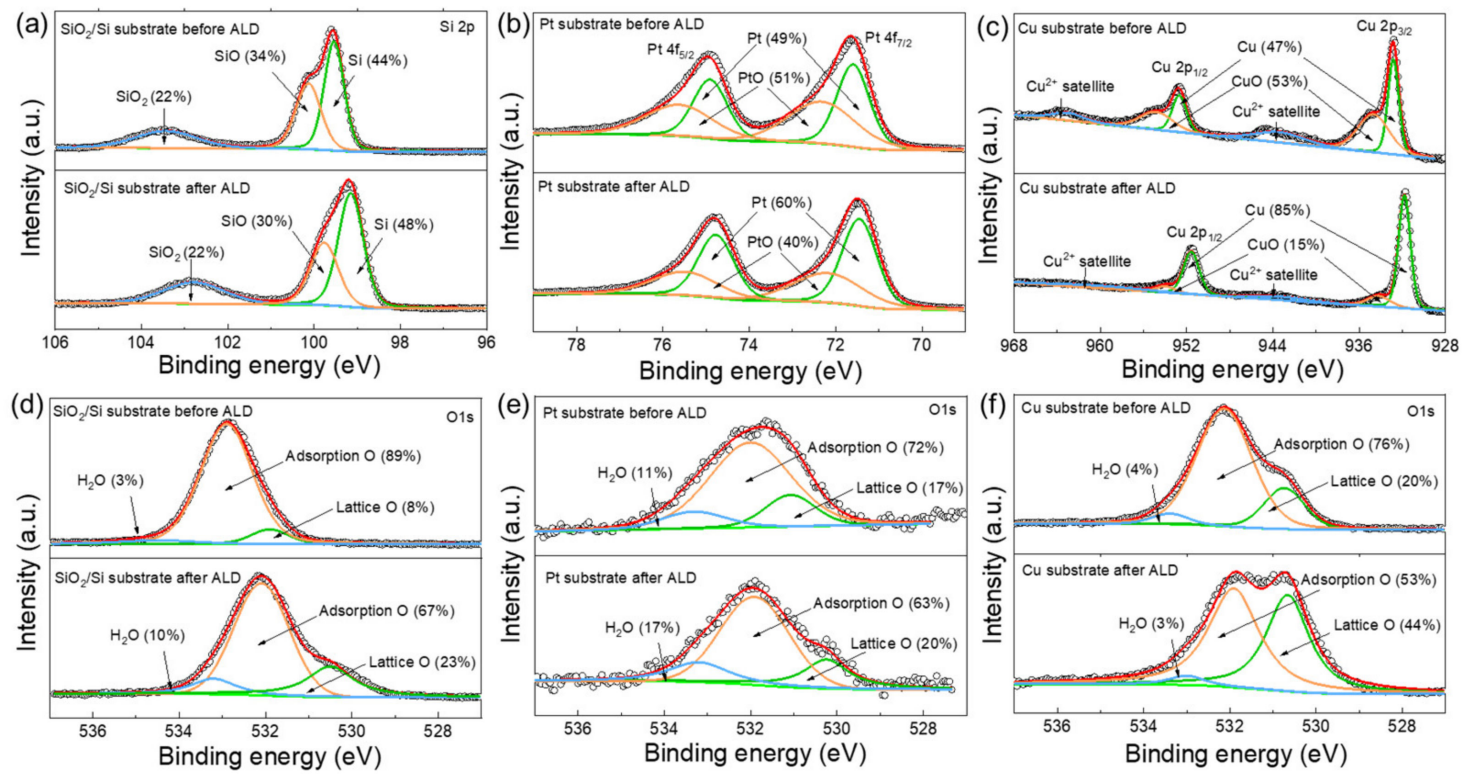

Figure 3. (a) $\mathrm{Si} 2 \mathrm{p}$ spectrum of $\mathrm{SiO}_{2} / \mathrm{Si}$ substrate before and after $\mathrm{MnO}_{\mathrm{x}}$ deposition. (b) $\mathrm{Pt} 4 \mathrm{f}$ spectrum of Pt substrate before and after $\mathrm{MnO}_{\mathrm{x}}$ deposition. (c) $\mathrm{Cu} 2 \mathrm{p}$ spectrum of $\mathrm{Cu}$ substrate before and after $\mathrm{MnO}_{\mathrm{x}}$ deposition. O 1s XPS spectrum of (d) $\mathrm{SiO}_{2} / \mathrm{Si}$ substrate, (e) $\mathrm{Pt}$ and (f) $\mathrm{Cu}$ substrates, respectively. 


\subsection{Selectivity Window of $M n O_{x}$}

To obtain high selectivity, it is necessary to suppress nuclei on the nongrowth areas. To quantify the selectivity, Equation (1) is as follows [32]:

$$
\text { Selectivity }=\frac{\theta_{G A}-\theta_{N G A}}{\theta_{G A}+\theta_{N G A}}
$$

where $\theta_{G A}$ and $\theta_{N G A}$ are the amount of target materials deposited on the growth and nongrowth areas, respectively. In the experiments, $\theta$ is simplified as the number of white points (Mn) per unit area in EDS mappings. The larger the number of white points of $\mathrm{Mn}$, the more $\mathrm{MnO}_{\mathrm{x}}$ deposited on the substrate. Thus, EDS mapping can be used as a semi-quantitative method to acquire the values of selectivity.

Through mathematical counting of Mn EDS mapping in Figure 1, the quantitative selectivity values are obtained. The selectivity on $\mathrm{Pt} / \mathrm{SiO}_{2}$ patterns increases from 0.39 to 0.5 through increasing temperature from 80 to $125^{\circ} \mathrm{C}$. Then, the selectivity slightly decreases to 0.48 at $215^{\circ} \mathrm{C}$ (Figure 4a). The selectivity between $\mathrm{Cu}$ and $\mathrm{SiO}_{2}$ surface is also analyzed, and there is almost no selective growth.
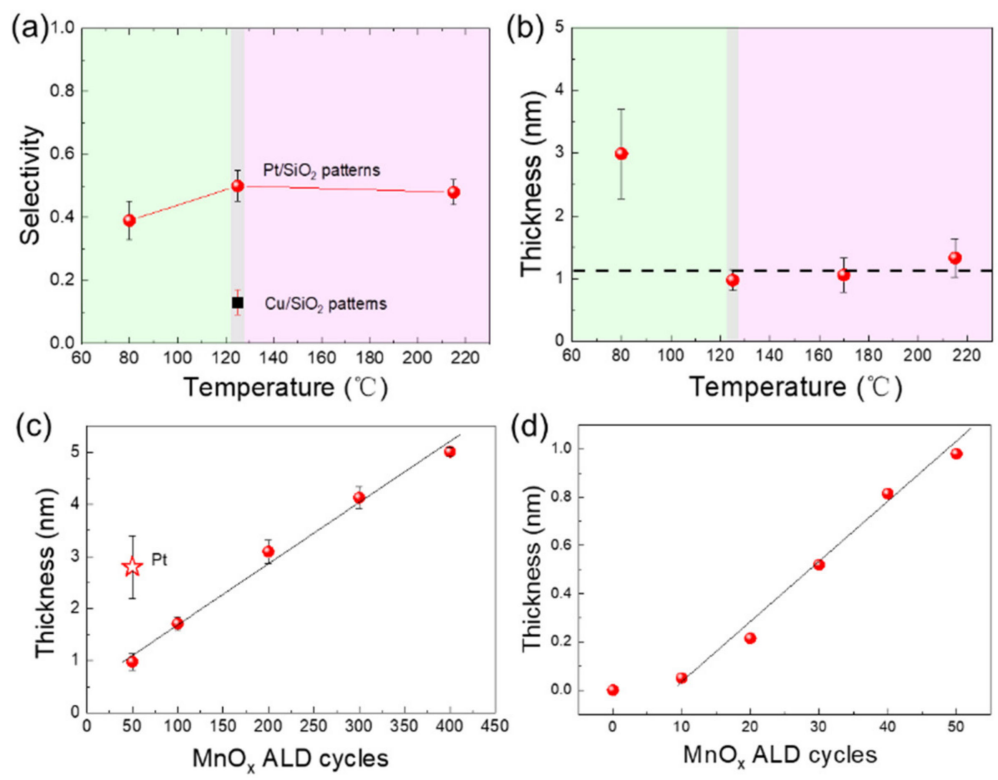

Figure 4. (a) The selectivity values as a function of the deposition temperature after $50 \mathrm{ALD} \mathrm{MnO}_{\mathrm{x}}$ cycles. The film thickness with respect to (b) deposition temperature and ALD cycle number (c) after 50 and (d) within 50 cycles on $\mathrm{SiO}_{2}$ substrate. The inset point in (c) shows the film thickness on the Pt surface at $125^{\circ} \mathrm{C}$ after 50 ALD cycles.

To study the relationship between the selectivity and the ALD temperature window, the growth rate is evaluated at the same temperature range (Figure $4 \mathrm{~b}$ ). As the deposition temperature increases from 80 to $125^{\circ} \mathrm{C}$, the growth rate of Mn oxides decreases quickly (50 ALD cycles are exploited). Further increasing the deposition temperature has minimal influence on film thickness, indicating that the temperatures ranging from 125 to $215^{\circ} \mathrm{C}$ are within the ALD window. It is found that high selectivity can be obtained only in the ALD window. The Mn precursors may condense at $80^{\circ} \mathrm{C}$, which causes weak selectivity.

The $\mathrm{MnO}_{\mathrm{x}}$ film thickness increases linearly on $\mathrm{SiO}_{2}$ substrate after 50 cycles (Figure 4c). The steady growth rate is $0.01 \mathrm{~nm} /$ cycle at $125^{\circ} \mathrm{C}$. The slow nucleation on the $\mathrm{SiO}_{2}$ regions is thought to be beneficial to achieve selective deposition. The growth rate within 50 ALD cycles is also presented in Figure 4d. The first 50 ALD cycles show two growth stages: $\sim 10$ cycles of nucleation incubation and a rapid growth stage indicating the acceleratory growth of nuclei islands. After 50 cycles, the surface of the $\mathrm{SiO}_{2}$ substrate is almost covered, and the nuclei islands begin to coalesce. The growth rate remains stable when further 
increasing ALD cycles. The surface gradually changes from $\mathrm{SiO}_{2}$ to $\mathrm{MnO}_{\mathrm{x}}$ layer after approximately 50 cycles, and the deposition rate decreases. When all the surfaces are completely covered with $\mathrm{MnO}_{\mathrm{x}}$, the substrate differences between $\mathrm{Pt}, \mathrm{Cu}$ and $\mathrm{SiO}_{2}$ are limited. For $\mathrm{MnO}_{\mathrm{x}}$ grown on ultrathin Pt films, it is found that the film thickness is $\sim 2.8 \mathrm{~nm}$ at 50 ALD cycles, which is much higher than that on the $\mathrm{SiO}_{2}$ substrate. The nucleation stage is also studied by examining the surface morphology of $A L D \mathrm{MnO}_{\mathrm{x}}$ ultrathin films with SEM and AFM (Figure S2 from Supplementary Materials). SEM image shows that there are a lot of nuclei islands on $\mathrm{SiO}_{2}$ at 50 ALD cycles. After $400 \mathrm{ALD}$ cycles, the particle size increases from $\sim 9.1$ to $\sim 16.7 \mathrm{~nm}$. AFM images show that initial $\mathrm{MnO}_{\mathrm{x}}$ deposition increases the surface roughness, then it decreases slowly from $\sim 0.80$ to $\sim 0.64 \mathrm{~nm}$ with increasing ALD cycles (see Figure S3 from Supplementary Materials).

The GPC is also checked by changing the pulse time of the precursors. The critical time of saturated adsorption of $\mathrm{Mn}$ precursors and water are $\sim 2$ and $\sim 3 \mathrm{~s}$, respectively (Figure S4a,b from Supplementary Materials). After the minimum dose time, the thickness maintains at $0.9 \sim 1.0 \mathrm{~nm}$ with increasing dosing time. It is found that the purge times longer than 30 and $60 \mathrm{~s}$ are enough to remove excess $\mathrm{Mn}(\mathrm{EtCp})_{2}$ and $\mathrm{H}_{2} \mathrm{O}$, respectively. The long pulse time of $\mathrm{Mn}(\mathrm{EtCp})_{2}(3 \mathrm{~s})$ and $\mathrm{H}_{2} \mathrm{O}$ (3s) in this work are to ensure sufficient adsorption and decomposition. The above results exhibit good self-limiting character, which lays a foundation for selective growth.

\section{The Origin of Selective Growth}

It is considered that ASD is mainly originated from competition between surface chemisorption, decomposition and so on [33]. To elucidate the origin of selective growth, the density functional theory (DFT) and nudged elastic band (NEB) are adopted to calculate the decomposition energy and energy barriers of ALD precursors on $\mathrm{Pt}, \mathrm{Cu}$ and $\mathrm{SiO}_{2}$ surfaces, as shown in Figure 5a. On the $\mathrm{SiO}-\mathrm{OH}$ surface, the following reactions between $\mathrm{Mn}(\mathrm{EtCp})_{2}$ and surface are considered as Equation (2) [34-36]:

$$
\mathrm{Mn}(\mathrm{EtCp})_{2}+\|-\mathrm{OH}=\|-\mathrm{O}-\mathrm{Mn}(\mathrm{EtCp})+\mathrm{H}-\mathrm{EtCp}
$$
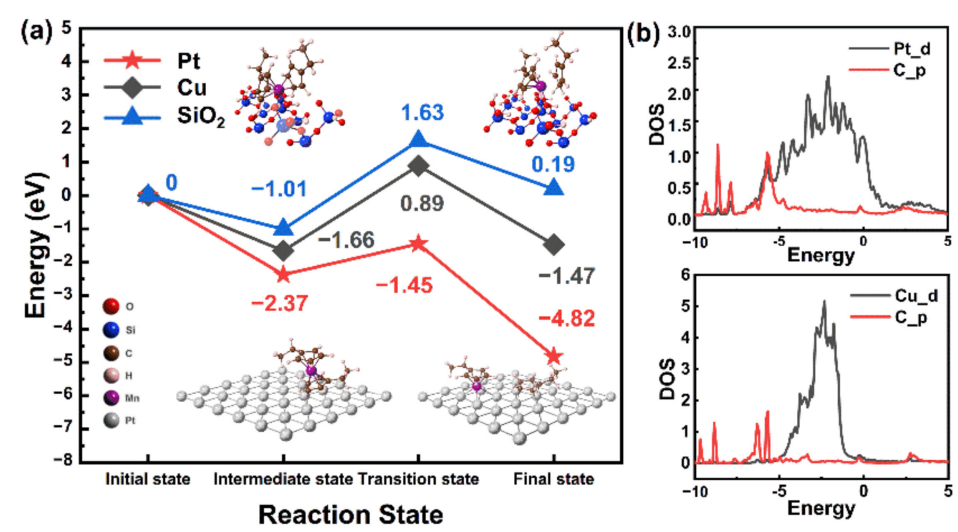

Figure 5. (a) Calculated energy diagrams of $\mathrm{Mn}$ precursors on the $\mathrm{Pt}, \mathrm{Cu}$ and $\mathrm{SiO}_{2}$ substrates and (b) a PDOS diagram of the adsorption of Mn precursors on $\mathrm{Pt}$ and $\mathrm{Cu}$ surfaces.

According to the previous study, the following decomposition reactions on the surface of $\mathrm{Pt}$ and $\mathrm{Cu}$ are considered as Equation (3) [37,38]:

$$
\mathrm{Mn}(\mathrm{EtCp})_{2}+\|-\mathrm{O}=\|-\mathrm{O}-\mathrm{Mn}(\mathrm{EtCp})+\|-\mathrm{O}-\mathrm{EtCp}
$$

Firstly, the adsorption energy of Mn precursor on three different substrates is analyzed. On the surface of $\mathrm{SiO}_{2}, \mathrm{Mn}(\mathrm{EtCP})_{2}$ is adsorbed on the $-\mathrm{OH}$ sites, and the adsorption energy is $-1.01 \mathrm{eV}$. In the decomposition step, the EtCp group combines with the $\mathrm{H}$ atom of $-\mathrm{OH}$ to form $\mathrm{H}$-EtCp, and the decomposition energy barrier is $2.64 \mathrm{eV} . \mathrm{Mn}(\mathrm{EtCp})_{2}$ is adsorbed 
on $\mathrm{Pt}$ and $\mathrm{Cu}$ surfaces with EtCp ligand facing the surface, and the adsorption energies are -1.66 and $-2.37 \mathrm{eV}$, respectively. The Mn-EtCp part slips from the EtCp group to the $\mathrm{Pt}$ and $\mathrm{Cu}$ surfaces, and the decomposition barriers are 0.92 and $2.55 \mathrm{eV}$, respectively.

The above results reveal that the growth of $\mathrm{Mn}(\mathrm{EtCp})_{2}$ has priority in the order of $\mathrm{Pt}>$ $\mathrm{Cu}>\mathrm{SiO}_{2}$. Then, the partial density of states (PDOS) of precursors adsorbed on $\mathrm{Pt}$ and $\mathrm{Cu}$ surface is analyzed (Figure $5 \mathrm{~b}$ ). From the PDOS diagram, the overlap of C_p orbital and $\mathrm{Pt} \_\mathrm{d}$ orbit indicates that a strong chemical bond is formed between the Pt surface and the precursors. In contrast, such an orbital overlap is absent on the $\mathrm{Cu}$ surface. The preferential growth of $\mathrm{MnO}_{\mathrm{x}}$ on the $\mathrm{Pt}$ surface may come from the favorable adsorption and decomposition process of Mn precursors.

To further explore the effect of substrates, the relationship between the selectivity and differences in electronegativity between $\mathrm{M}$ and $\mathrm{O}$ is presented (Figure 6a). The Pauling electronegativity of $\mathrm{Pt}, \mathrm{Cu}, \mathrm{Si}$ and $\mathrm{O}$ are 2.28, 2.00, 1.90 and 3.44, respectively [39]. The differences in electronegativity between $\mathrm{M}(\mathrm{M}=\mathrm{Pt}, \mathrm{Cu}$ and $\mathrm{Si})$ and $\mathrm{O}$ decrease in the order of $\mathrm{Si}-\mathrm{O}$ (1.54), $\mathrm{Cu}-\mathrm{O}$ (1.44) and $\mathrm{Pt}-\mathrm{O}$ (1.16). It is found that selectivity is negatively correlated with the differences in electronegativity. Smaller differences in electronegativity between $\mathrm{M}-\mathrm{O}$ may lead to weaker bonding energy [40,41], which may influence the chemisorption of $\mathrm{Mn}$ precursors on $\mathrm{Si}-\mathrm{O}, \mathrm{Cu}-\mathrm{O}$ and $\mathrm{Pt}-\mathrm{O}$ surfaces. The absolute value of adsorption energy rises with the order of $\mathrm{Si}-\mathrm{O}, \mathrm{Cu}-\mathrm{O}$ and $\mathrm{Pt}-\mathrm{O}$ from the DFT calculations, and the reaction barrier decreases with the same order. The differences in electronegativity may also become a supplemental explanation of selectivity for some precursors on certain substrates. The origin of selective deposition is the differences in chemisorption between two surfaces. At the nucleation stage, the precursors are chemically adsorbed on the surface oxygen groups to form $\mathrm{M}-\mathrm{O}-\mathrm{Mn}$ bonds. The bonding energy of $\mathrm{M}-\mathrm{O}$, which is affected by the electronegativity, thus affects chemical adsorption. Smaller differences in electronegativity between $\mathrm{M}-\mathrm{O}$ may lead to weak bonding, which is beneficial to reduce the reaction barrier.
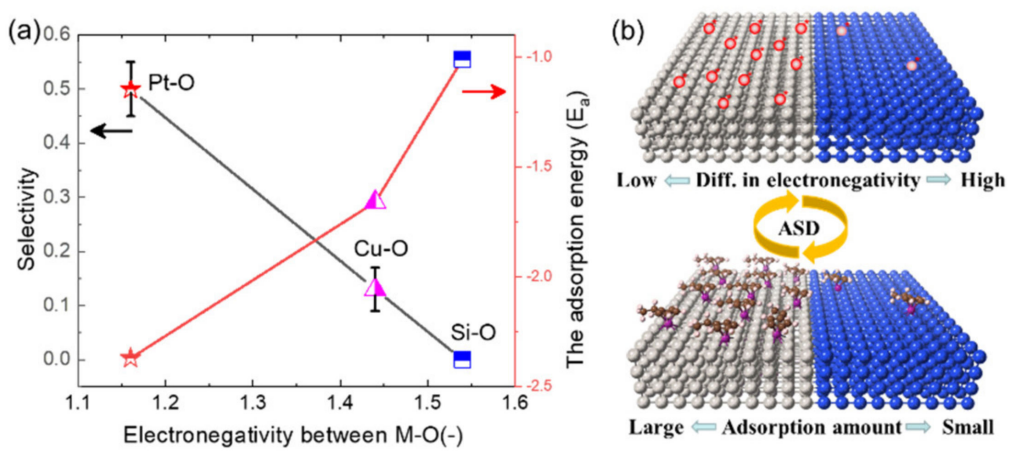

Figure 6. (a) The selectivity values (black line) and the adsorption energy (red line) plotted versus the differences in electronegativity of $\mathrm{M}$-oxide $(\mathrm{M}=\mathrm{Si}, \mathrm{Cu}, \mathrm{Pt})$ underlayers. (b) Schematic for the adsorption amount of $\mathrm{Mn}(\mathrm{EtCp})_{2}$ on the patterned substrates with different D-value in electronegativity.

\section{Materials and Methods}

\subsection{Substrate Preparation}

$\mathrm{Cu}$ and Pt films were deposited by sputtering onto Si(100) wafers using an argonbased plasma. The film thickness is a few nanometers. The surface roughness of the Pt and $\mathrm{Cu}$ substrates are less than $5 \mathrm{~nm}$. $\mathrm{Si}(100)$ substrates, with a layer of $\mathrm{SiO}_{2}$ around $20 \AA$ thick, were cleaned with acetone and deionized water. The Pt and $\mathrm{Cu}$ samples were annealed in hydrogen to remove the oxide layers as much as possible. If they were not immediately used after cleaning, the substrates are stored in the argon atmosphere until use.

\subsection{Growth Conditions}

The ALD reactions were performed in a custom hot-walled ALD reactor (Material Design and Nano-manufacturing center @ HUST, Wuhan, China) at $50-250{ }^{\circ} \mathrm{C}$, and $50 \mathrm{~Pa}$ 
of argon pressure provided by an $80 \mathrm{Sccm}$ continuous argon purge (99.999\%, Prepurified). ALD of $\mathrm{MnO}_{x}$ was carried out using (a) $\mathrm{Mn}(\mathrm{EtCp})_{2}$ ( $>98 \%$, Aimou Yuan, Nanjing, China) and (b) $\mathrm{H}_{2} \mathrm{O}$ (ultrapure deionized water). The temperature of the precursor's container was controlled at $100{ }^{\circ} \mathrm{C}$, in which argon was diverted over the headspace of the liquid precursors during dosing. The temperature of the pipeline was $20^{\circ} \mathrm{C}$ higher than that of the container to prevent condensation of $\mathrm{Mn}$ precursors. The inset of Figure S4a (from Supplementary Materials) shows the typical half-reactions process of $\mathrm{Mn}(\mathrm{EtCp})_{2}$ and $\mathrm{H}_{2} \mathrm{O}$ dosing. The base pressure of the ALD chamber was about $113 \mathrm{~Pa}$, the peak pressure of the $\mathrm{Mn}(\mathrm{EtCP})_{2}$ and $\mathrm{H}_{2} \mathrm{O}$ dose were tuned to a level of $\sim 20$ and $\sim 7 \mathrm{~Pa}$ above the base pressure, respectively. The ALD reactions were carried out in a circulate of $\mathrm{Mn}(\mathrm{EtCp})_{2}$, purge, $\mathrm{H}_{2} \mathrm{O}$ and purge sequence, with a typical time of $3,30,3$, and $60 \mathrm{~s}$.

\subsection{Characterization of $\mathrm{MnO}_{x}$}

The film thickness on $\mathrm{SiO}_{2}$ was measured by a spectroscopic ellipsometer (SE, M200X, J. A. Woollam Co., Inc., Lincoln, NE, USA). Additionally, $\mathrm{MnO}_{\mathrm{x}}$ thickness on ALD $\mathrm{Pt}$ was acquired by SE after $50 \mathrm{ALD}$ cycles at $125^{\circ} \mathrm{C}$. The wavelength of light ranged from 250 to $1000 \mathrm{~nm}$. The software was Complete EASE, and a modified Cauchy model was used to fit the ellipsometer data. Patterned $\mathrm{Pt} / \mathrm{SiO}_{2}$ and $\mathrm{Cu} / \mathrm{SiO}_{2}$ substrates were observed by optical microscope. The surface morphology was analyzed by SEM (attached EDS, SU3900, HITACHI, Tokyo, Japan) and AFM (Agilent 5500, Santa Clara, CA, USA) for 0, 50 and $400 \mathrm{MnO}_{\mathrm{x}}$ ALD cycles. EDS mappings of platinum and manganese were measured on $\mathrm{Pt} / \mathrm{SiO}_{2}$ patterns after 50 ALD MnO cycles at 80,125 , and $215^{\circ} \mathrm{C}$. The surface composition was evaluated by X-ray photoelectron spectrograph (XPS, AXIS-ULTRA DLD$600 \mathrm{~W}$, Shimadzu-Kratos Co., Manchester, UK) with an Al K $\alpha$ X-ray (h $v=1486.6 \mathrm{eV})$ after 50 ALD cycles on $\mathrm{Cu}, \mathrm{Pt}$ and $\mathrm{SiO}_{2}$ substrates. All the spectrum were calibrated using C 1 s $(285 \mathrm{eV})$. The peaks were separated by XPS peak software, and the background was removed by Shirley type. The peak areas of $\mathrm{Mn}^{2+}, \mathrm{Mn}^{2+}$ satellite, $\mathrm{Mn}^{3+}$ and $\mathrm{Mn}^{4+}$ within $\mathrm{Mn} 2 \mathrm{p}_{3 / 2}$ were two times higher than that of $\mathrm{Mn} 2 \mathrm{p}_{1 / 2}$, respectively. The ratio of Lorentzian-Gaussian was 20\%. The peak area represented the content of different bonds.

\subsection{DFT Calculation}

DFT calculations were carried out using the first-principles plane-wave pseudopotential formulation implemented in the Vienna ab-initio Simulation Package (version 5.4.4, University of Vienna, Vienna, Austria). The exchange-correlation functional was in the form of Perdew-Burke-Ernzerhof with the generalized gradient approximation [42]. Van der Waals interactions were also accounted to be based on experience. The cutoff energy was $400 \mathrm{eV}$ on the basis of the plane-wave. A k-mesh of $3 \times 3 \times 1$ was applied to ensure the energy convergence to $1 \mathrm{meV}$, and the residual force acting on each atom is less than $0.05 \mathrm{eV} / \AA$. A $5 \times 5 \times 4 \mathrm{Pt}(111)$ slabs model, $5 \times 5 \times 4 \mathrm{Cu}(111)$ slabs model and 13 layers hydroxylated $\mathrm{SiO}_{2}$ slabs model was built to resemble the $\mathrm{Pt}, \mathrm{Cu}$ and $\mathrm{SiO}_{2}$ surface on the experiment, respectively. The adsorption energy $\left(\mathrm{E}_{\mathrm{a}}\right)$ of the precursor on the $\mathrm{Pt}$ surface was defined by the Equation (4) [38]:

$$
E_{a}=E_{a d s}^{*}-E^{*}-E_{M n(E t C p) 2}
$$

where $E^{*}$ ads is the total energy of the slabs; $E^{*}$ and $E_{\mathrm{Mn}(\mathrm{EtCp}) 2}$ are the energies of the slabs and precursor molecule, respectively. The decomposition energy $\left(E_{d}\right)$ is calculated by the Equation (5):

$$
E_{d}=E_{d e c}^{*}-E^{*}-E_{M n(E t C p) 2}
$$

where $E_{\text {dec }}^{*}$ is the total energy of the surface with the precursor decomposed. The nudged elastic band (NEB) was used to search the minimum energy path (MEP) of the precursor dissociation on the Pt surface and locate the transition state between two local minima. Six intermediate images were interpolated between the adsorbed state and decomposed state. 


\section{Conclusions}

In this work, $\mathrm{MnO}_{\mathrm{x}}$ films are fabricated with ALD using bis(ethylcyclopentadienyl) manganese $\left(\mathrm{Mn}(\mathrm{EtCp})_{2}\right)$ and $\mathrm{H}_{2} \mathrm{O}$. Inherently selective growth is demonstrated on patterned $\mathrm{Pt} / \mathrm{SiO}_{2}$ and $\mathrm{Cu} / \mathrm{SiO}_{2}$ substrates. It is found that $\mathrm{MnO}_{\mathrm{x}}$ preferential deposits on $\mathrm{Pt}$, then followed by $\mathrm{Cu}$ and $\mathrm{SiO}_{2}$. The selectivity improves with increasing deposition temperature within the ALD window. Meanwhile, it is found that the calculated selectivity has a negative relationship with enlarging the electronegativity differences between $\mathrm{M}(\mathrm{M}=\mathrm{Si}$, $\mathrm{Cu}$ and $\mathrm{Pt}$ ) and $\mathrm{O}$. The origin of selective deposition is the differences of chemisorption between two surfaces. The bonding energy of $\mathrm{M}-\mathrm{O}$ is affected by the electronegativity, thus affects chemical adsorption. Smaller differences in electronegativity between $\mathrm{M}-\mathrm{O}$ may lead to weak bonding, which is beneficial to reduce the reaction barrier. The differences in electronegativity may also become a supplemental explanation of selectivity for some precursors on certain substrates, which shows a possible method the further development and prediction of selective ASD processes.

Supplementary Materials: The following are available online, Figure S1: Optical images of patterned (a) $\mathrm{Pt} / \mathrm{SiO}_{2}$ and (b) $\mathrm{Cu} / \mathrm{SiO}_{2}$ substrate, SEM images of amplified (c) $\mathrm{Pt} / \mathrm{SiO}_{2}$ and (d) $\mathrm{Cu} / \mathrm{SiO}_{2}$ patterns after 50 ALD cycles. Figure S2: SEM images of (a) bare Si substrate; (b) 50 ALD MnO cycles; $^{2}$ (c) 400 ALD $\mathrm{MnO}_{\mathrm{x}}$ cycles; AFM images of (d) bare Si substrate; (e) 50 ALD MnO cycles; (f) 400 ALD $\mathrm{MnO}_{\mathrm{x}}$ cycles. Figure S3: Surface roughness as a function of ALD $\mathrm{MnO}_{\mathrm{x}}$ cycles. Figure S4: Film thickness with respect to (a) $\mathrm{Mn}(\mathrm{EtCp})_{2}$ pulse time and (b) $\mathrm{H}_{2} \mathrm{O}$ pulse time. The inset in (a) is the pressure of dosing $\mathrm{Mn}(\mathrm{EtCp})_{2}$ and $\mathrm{H}_{2} \mathrm{O}$ as a function of time. The deposition temperature is $125^{\circ} \mathrm{C}$, for (a) and (b).

Author Contributions: Conceptualization, Y.-C.L., K.C. and R.C.; methodology, M.G.; software, Y.X.L., Y.-W.W., B.S.; validation, J.-M.Z.; formal analysis, K.C.; data curation, Y.-C.L.; writing-original draft preparation, Y.-C.L.; writing—review and editing, Y.-C.L.; visualization, Y.-C.L.; supervision, K.C., R.C.; project administration, K.C.; funding acquisition, K.C., B.S. and R.C. All authors have read and agreed to the published version of the manuscript.

Funding: This work is supported by the National Natural Science Foundation of China (51835005, 51871103, and 51911540476), the Hubei Province Natural Science Foundation for innovative research groups (2020CFA030) and the Independent Innovation Research Fund of Huazhong University of Science and Technology (2019kfyXMBZ025).

Data Availability Statement: Not applicable.

Acknowledgments: The authors would also like to acknowledge the support from the Analytic Testing Center and the Flexible Electronics Research Center of the HUST.

Conflicts of Interest: The authors declare no conflict of interest.

Sample Availability: Samples of the compounds are available from the authors.

\section{References}

1. Mackus, A.J.M.; Merkx, M.J.M.; Kessels, W.M.M. From the bottom-up: Toward area-selective atomic layer deposition with high selectivity. Chem. Mater. 2018, 31, 2-12. [CrossRef] [PubMed]

2. Chen, R.; Li, Y.C.; Cai, J.M.; Cao, K.; Lee, H. Atomic level deposition to extend Moore's law and beyond. Int. J. Extrem. Manuf. 2020, 2, 022002. [CrossRef]

3. Parsons, G.N.; Clark, R.D. Area-selective deposition: Fundamentals, applications, and future outlook. Chem. Mater. 2020, 32, 4920-4953. [CrossRef]

4. George, S.M. Atomic layer deposition: An overview. Chem. Rev. 2010, 110, 111-131. [CrossRef] [PubMed]

5. Mackus, A.J.M.; Bol, A.A.; Kessels, W.M.M. The use of atomic layer deposition in advanced nanopatterning. Nanoscale 2014, 6, 10941-10960. [CrossRef]

6. Adhikari, S.; Selvaraj, S.; Kim, D.H. Progress in powder coating technology using atomic layer deposition. Adv. Mater. Interfaces 2018, 1800581, 1-20. [CrossRef]

7. Yanguas-Gil, A.; Libera, A.; Jeffrey, W.E. Modulation of the growth per cycle in atomic layer deposition using reversible surface functionalization. Chem. Mater. 2013, 25, 4849-4860. [CrossRef]

8. Lu, J.; Low, K.B.; Lei, Y.; Libera, J.A.; Nicholls, A.; Stair, P.C.; Elam, J.W. Toward atomically-precise synthesis of supported bimetallic nanoparticles using atomic layer deposition. Nat. Commun. 2014, 5, 1-9. [CrossRef] 
9. Mameli, A.; Karasulu, B.; Verheijen, M.A.; Barcones, B.; Macco, B.; Mackus, A.; Kessels, M.; Roozeboom, F. Area-selective atomic layer deposition of $\mathrm{ZnO}$ by area activation using electron beam induced deposition. Chem. Mater. 2019, 31, 1250-1257. [CrossRef]

10. Soethoudt, J.; Crahaij, S.; Conard, T.; Delabie, A. Impact of $\mathrm{SiO}_{2}$ surface composition on trimethylsilane passivation for areaselective deposition. J. Mater. Chem. C 2019, 7, 11911-11918. [CrossRef]

11. Lu, J.L.; Elam, J.W. Low temperature ABC-type Ru atomic layer deposition through consecutive dissociative chemisorption, combustion, and reduction steps. Chem. Mater. 2015, 27, 4950-4956. [CrossRef]

12. Masango, S.S.; Peng, L.; Marks, L.D.; Duyne, R.P.V.; Stair, P.C. Nucleation and growth of silver nanoparticles by AB and ABC-type atomic layer deposition. J. Phys. Chem. C 2014, 118, 17655-17661. [CrossRef]

13. Weber, M.J.; Mackus, A.; Verheijen, M.A.; Marel, C.; Kessels, W. Supported core/shell bimetallic nanoparticles synthesis by atomic layer deposition. Chem. Mater. 2012, 24, 2973-2977. [CrossRef]

14. Weber, M.J.; Verheijen, M.A.; Bol, A.A.; Kessels, W.M.M. Sub-nanometer dimensions control of core shell nanoparticles prepared by atomic layer deposition. Nanotechnology 2015, 26, 094002. [CrossRef] [PubMed]

15. Bobb-Semple, D.; Nardi, K.L.; Draeger, N.; Hausmann, D.M.; Bent, S.F. Area-selective atomic layer deposition assisted by self-assembled monolayers a comparison of $\mathrm{Cu}, \mathrm{Co}, \mathrm{W}$, and Ru. Chem. Mater. 2019, 31, 1635-1645. [CrossRef]

16. Merkx, M.J.M.; Vlaanderen, S.; Faraz, T.; Verheijen, M.A.; Kessels, W.M.M.; Mackus, A.J.M. Area-selective atomic layer deposition of TiN using aromatic inhibitor molecules for metal/dielectric selectivity. Chem. Mater. 2020, 32, 7788-7795. [CrossRef]

17. Cian, C.; Tobias, W.; Morris, M.A. Enabling large-area selective deposition on metal-dielectric patterns using polymer brush deactivation. J. Phys. Chem. C 2018, 122, 14698-14705.

18. Cao, K.; Cai, J.; Chen, R. Inherently selective atomic layer deposition and applications. Chem. Mater. 2020, 32, 2195-2207. [CrossRef]

19. Wang, Y.P.; Wu, X.; Liu, W.J.; Zhang, D.W.; Ding, S.J. Plasma-enhanced atomic layer deposition of low resistivity and ultrathin manganese oxynitride films with excellent resistance to copper diffusion. ACS Appl. Electron. Mater. 2020, 2, 1653-1660. [CrossRef]

20. Choi, J.; Byun, W.J.; Kang, D.H.; Lee, J.K. Porous manganese oxide networks as high-capacity and high-rate anodes for Lithium-Ion batteries. Energies 2021, 14, 1299. [CrossRef]

21. Seo, W.S.; Jo, H.H.; Lee, K.; Kim, B.; Oh, S.J.; Park, J.T. Size-dependent magnetic properties of colloidal $\mathrm{Mn}_{3} \mathrm{O}_{4}$ and $\mathrm{MnO}$ nanoparticles. Angew. Chem. Int. Ed. 2004, 116, 1135-1137. [CrossRef]

22. Burton, B.B.; Fabreguette, F.H.; George, S.M. Atomic layer deposition of MnO using bis(ethylcyclopentadienyl)manganese and $\mathrm{H}_{2} \mathrm{O}$. Thin Solid Films 2009, 517, 5658-5665. [CrossRef]

23. Young, M.J.; Hare, C.D.; Musgrave, C.B.; George, S.M. Rapid growth of crystalline $\mathrm{Mn}_{5} \mathrm{O}_{8}$ by self-limited multilayer deposition using $\mathrm{Mn}(\mathrm{EtCp})_{2}$ and $\mathrm{O}_{3}$. ACS Appl. Mater. Interfaces 2016, 8, 18560-18569. [CrossRef] [PubMed]

24. Nieminen, H.E.; Miikkulainen, V.; Settipani, D.; Simonelli, L.; Hönicke, P.; Zech, C.; Kayser, Y.; Beckhoff, B.; Honkanen, A.; Heikkilä, M.J.; et al. Intercalation of Lithium ions from gaseous precursors into $\beta-\mathrm{MnO}_{2}$ thin films deposited by atomic layer deposition. J. Phys. Chem. C 2019, 123, 15802-15814. [CrossRef]

25. Koike, J.; Hosseini, M.; Hai, H.T.; Ando, D.; Sutou, Y. Material innovation for MOL, BEOL, and 3D Integration. IEDM 2017, 32, $1-4$.

26. Kawasaki, H.; Matsumoto, K.; Nagai, H.; Kikuchi, Y.; Chang, P. Atomic Layer Deposition of MnO for Cu Capping Layer in $\mathrm{Cu} /$ low-k Interconnects. In Proceedings of the IEEE International Interconnect Technology Conference, San Jose, CA, USA, 20-23 May 2014; pp. 315-318.

27. Phuong, N.M.; Sutou, Y.; Koike, J. Structural characterization of a manganese oxide barrier layer formed by chemical vapor deposition for advanced interconnects application on SiOC dielectric substrates. J. Phys. Chem. C 2013, 117, 160-164. [CrossRef]

28. Maeda, E.; Nabatame, T.; Hirose, M.; Inoue, M.; Ohi, A.; Ikeda, N.; Kiyono, H. Correlation between $\mathrm{SiO}_{2}$ growth rate and difference in electronegativity of metal-oxide underlayers for plasma enhanced atomic layer deposition using tris(dimethylamino)silane precursor. J. Vac. Sci. Technol. A 2020, 38, 032409. [CrossRef]

29. Mattelaer, F.; Vereecken, P.M.; Dendooven, J.; Detavernier, C. Deposition of $\mathrm{MnO}$ anode and $\mathrm{MnO}_{2}$ cathode thin films by plasma enhanced atomic layer deposition using the Mn(thd) 3 precursor. Chem. Mater. 2015, 27, 3628-3635. [CrossRef]

30. Yang, J.; Cao, K.; Gong, M.; Shan, B.; Chen, R. Atomically decorating of $\mathrm{MnO}_{\mathrm{x}}$ on palladium nanoparticles towards selective oxidation of benzyl alcohol with high yield. J. Catal. 2020, 386, 60-69. [CrossRef]

31. Singh, J.A.; Thissen, N.F.W.; Kim, W.; Johnson, H.; Kessels, W.M.M.; Bol, A.A.; Bent, S.F.; Mackus, A.J.M. Area-selective atomic layer deposition of metal oxides on noble metals through catalytic oxygen activation. Chem. Mater. 2018, 30, 663-670. [CrossRef]

32. Parsons, G.N. Functional model for analysis of ALD nucleation and quantification of area-selective deposition. J. Vac. Sci. Technol. A 2019, 37, 020911. [CrossRef]

33. Grillo, F.; Soethoudt, J.; Marques, E.A.; Martín, L.; Dongen, K.V.; Ommen, J.R.; Delabie, A. Area-selective deposition of Ruthenium by area-dependent surface diffusion. Chem. Mater. 2020, 32, 9560-9572. [CrossRef]

34. Mameli, A.; Kuang, Y.; Aghaee, M.; Ande, C.K.; Karasulu, B.; Creatore, M.; Mackus, A.J.M.; Kessels, W.M.M.; Roozeboom, F. Area-selective atomic layer deposition of $\mathrm{In}_{2} \mathrm{O}_{3}$ : $\mathrm{H}$ using a $\mu$-plasma printer for local area activation. Chem. Mater. 2017, 29, 921-925. [CrossRef] [PubMed]

35. Minjauw, M.M.; Rijckaert, H.; Van Driessche, I.; Detavernier, C.; Dendooven, J. Nucleation enhancement and area-selective atomic layer deposition of Ruthenium using $\mathrm{RuO}_{4}$ and $\mathrm{H}_{2}$ gas. Chem. Mater. 2019, 31, 1491-1499. [CrossRef] 
36. Mcdonnell, S.; Longo, R.C.; Seitz, O.; Ballard, J.B.; Wallace, R.M. Controlling the atomic layer deposition of titanium dioxide on silicon: Dependence on surface termination. J. Phys. Chem. C 2013, 117, 20250-20259. [CrossRef]

37. Zyulkov, I.; Madhiwala, V.; Voronina, E.N.; Snelgrove, M.; Armini, S. Area-selective ALD of Ru on nanometer-scale Cu lines through dimerization of amino-functionalized alkoxy silane passivation films. ACS Appl. Mater. Interfaces 2020, 12, 4678-4688. [CrossRef]

38. Wen, Y.; Cai, J.; Zhang, J.; Yang, J.; Shi, L.; Cao, K.; Chen, R.; Shan, B. Edge-Selective Growth of MCp $2(\mathrm{M}=\mathrm{Fe}, \mathrm{Co}$, and Ni) Precursors on Pt nanoparticles in atomic layer deposition: A combined theoretical and experimental study. Chem. Mater. 2018, 31, 101-111. [CrossRef]

39. Huheey, J.E.; Keiter, E.A.; Keiter, R.L. Inorganic Chemistry: Principles of Structure and Reactivity, 4th ed.; HarperCollins College Publishers: New York, NY, USA, 1993.

40. Match, R.L. Theory of the chemical bond. 6. Accurate relationship between bond energies and electronegativity differences. J. Am. Chem. Soc. 1983, 105, 4859-4862. [CrossRef]

41. Sanderson, R.T. Electronegativity and bond energy. J. Am. Chem. Soc. 1983, 105, 2259-2261. [CrossRef]

42. Perdew, J.P.; Burke, K.; Ernzerhof, M. Generalized gradient approximation made simple. Phys. Rev. Lett. 1996, 77, $3865-3868$. [CrossRef] 